Portland State University

PDXScholar

Summer 7-13-2016

\title{
Social Support and Depression Symptomatology Post Injury in Division 1 Athletes
}

\author{
Alyssa Catherine Tiedens \\ Portland State University
}

Follow this and additional works at: https://pdxscholar.library.pdx.edu/open_access_etds

Part of the Psychiatric and Mental Health Commons, Social Psychology Commons, and the Sports Studies Commons

Let us know how access to this document benefits you.

\section{Recommended Citation}

Tiedens, Alyssa Catherine, "Social Support and Depression Symptomatology Post Injury in Division 1 Athletes" (2016). Dissertations and Theses. Paper 3126.

https://doi.org/10.15760/etd.3122

This Thesis is brought to you for free and open access. It has been accepted for inclusion in Dissertations and Theses by an authorized administrator of PDXScholar. Please contact us if we can make this document more accessible: pdxscholar@pdx.edu. 
Social Support and Depression Symptomatology Post Injury in Division 1 Athletes

by

Alyssa Catherine Tiedens

A thesis submitted in partial fulfillment of the

requirements for the degree of

\author{
Master of Science \\ in \\ Health Studies
}

Thesis Committee:

Gary Brodowicz, Chair

James Wallis

Randy Logan

Portland State University

2016 


\begin{abstract}
The way in which an athlete responds to the injury-emotionally, behaviorally, and cognitively — can significantly affect the athlete's mental health in a negative way if not handled appropriately. There are different forms of social support that are known to be helpful with coping during specific stages of injury. The purpose of this study was to examine the relationship between perceived levels of social support and depression symptomatology post injury in Division 1 collegiate athletes at Portland State University (PSU).
\end{abstract}

Participants were PSU student athletes $(n=115)$. Variables: social support amount (SSQN), social support satisfaction (SSQS), and depression symptomatology (CESD-R) score. Selected injured participants $(n=3)$ completed a 20-minute interview regarding their injury, their social support, and how each affected their mental health.

Females reported more social support sources (SSQN) as well as a higher satisfaction of their social support (SSQS) than males. Non-injured student athletes appeared to have fewer social support sources as well as less social support satisfaction than injured student athletes. Of the total study sample, 27.8 percent met the criteria for some kind of depressive symptom concern.

The study confirmed gender characteristics regarding help-seeking behavior, trends of depression symptomatology, and social support preferences. Overall the current study's findings indicate a need for further research regarding social support and depression symptomatology, examining injured and non-injured student athletes. 


\section{Table of Contents}

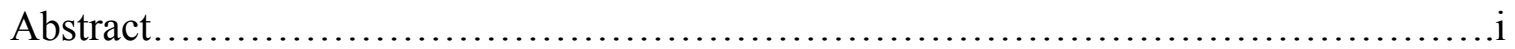

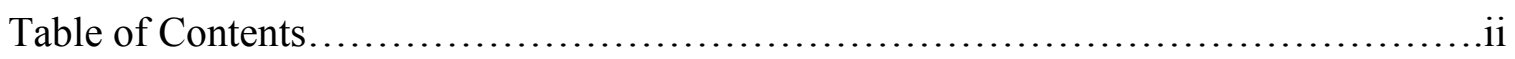

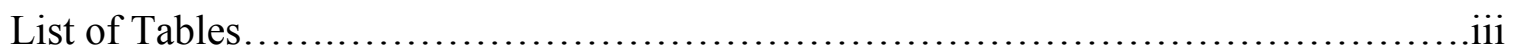

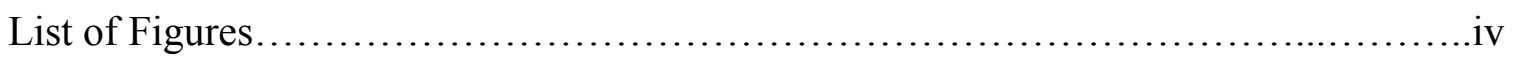

Chapter 1

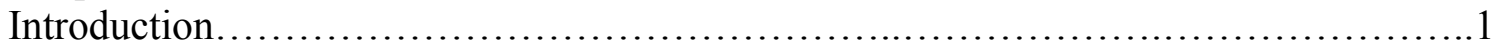

Chapter 2

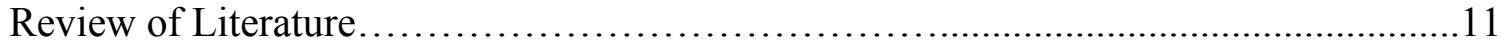

Chapter 3

Methods................................................................... 20

Chapter 4

Results...................................................................... 24

Chapter 5

Discussion............................................................... 32

References..................................................................

Appendices

A. Demographic Survey...............................................42

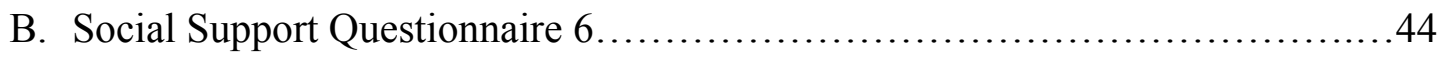

C. The Center for Epidemiological Studies Depression Scale Revised.............48

D. Interview Guide.................................................. 51

E. Informed Consent................................................ 52

F. Interview Informed Consent.............................................

G. Recruitment Email................................................54

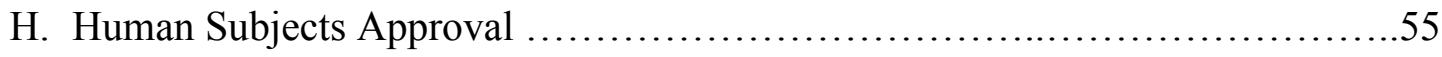




\section{Table 1}

\section{List of Tables}

Amount of social support (SSQN), social support satisfaction (SSQS), and depression symptomatology score (CESD-R)

Table 2

Amount of social support (SSQN), social support satisfaction (SSQS), and depression symptomatology score (CESD-R).

Table 3

Pearson correlations for social support satisfaction (SSQS) vs. depression symptomatology

score (CESD-R) and amount of social support (SSQN) vs. depression symptomatology score (CESD-R) in injured and non-injured athletes.................................. 31

Table 4

Pearson correlations for social support satisfaction (SSQS) vs. depression symptomatology score (CESD-R) and amount of social support (SSQN) vs. depression symptomatology score (CESD-R) in males and females........................... 31 
Figure 1

\section{List of Figures}

Integrated model depicting the psychological response to sport injury and rehabilitation

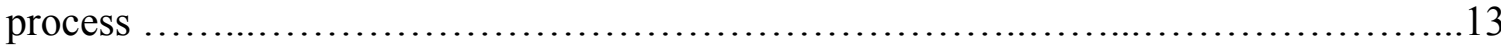

Figure 2

Average amount of social support (SSQN) reported by sport.........................26

Figure 3

Average social support satisfaction (SSQS) reported by sport

Figure 4

Average social support satisfaction (SSQS) reported by depressive symptom category (CESD-R)

Figure 5

Average depression symptomatology score (CESD-R) reported by sport...............29

Figure 6

Total number of athletes in each depressive symptom category (CESD-R) 30 


\section{Chapter 1}

Introduction

Becoming injured in collegiate athletics is a detrimental event, yet many athletes can expect to suffer from an injury at some point in their athletic career. Although most injuries do not result in significant time loss, it is noted that one injury is expected to occur every five practices and one injury every two games (Hootman, Dick, \& Agel, 2007). The psychological processes that occur during the period of injury/recovery will be different for all athletes. The way in which an athlete responds to the injury - emotionally, behaviorally, and cognitively — can significantly affect the athlete's mental health in a negative way if not handled appropriately.

Some athletes will cope with their injury adequately, and recover to their full athletic potential without any concerns about changes in their mental health, whereas others will have difficulty coping with the injury and subsequent recovery process. These issues can begin with depression symptomatology and develop as deep as clinical depression. College athletes are often considered to be protected from depression by high levels of physical activity, social support, and self-esteem that are common factors in athletic team environments (Williams \& Galliher, 2006). While these factors can have supportive effects, depression among collegiate athletes has grown more common. For example, a study in the United States found that $21.4 \%$ of college athletes reported symptoms of depression, which — although less than the rate of 33\% among general college students - is still a cause for concern (Yang, Peek-Asa, Corlette, Cheng, Foster, \& Albright, 2007). 
There are a handful of coping options that can be used to prevent the risk of depression symptomatology or depression, including social support, exercise, religion/spirituality, goal setting, venting, etc. (Wheeler, 2007). Because athletes have such a high risk of becoming injured, it is important for health care providers to be aware of ways they can help facilitate proper coping techniques with these athletes.

\section{Psychological Response to Athletic Injury}

There is a fifty percent chance that an athlete will become injured while participating in any athletic activity (Ballard, 1996). While this may not be surprising, the high risk of injury establishes a need for greater understanding about the consequences of athletic injuries, specifically concentrating on the way the mind and body respond to these injuries. By creating a stronger focus on the mind after an injury, there is a potential for physical advances in the injury recovery process, as well as psychological advances to support the athlete through the recovery process and throughout the rest of his or her career.

The psychological response to athletic injury is a very complex, important process that each individual experiences in many different ways. After an injury has occurred, the athlete may experience a series of emotions and thoughts that could affect the timeline of recovery and return to competition, as well as his or her long-term mental health. The most common emotions reported after injury includes anxiety, fear, anger, confusion, depression, and decreases in vigor (Tracey, 2003; Smith et al., 1993). The sources of these emotions are related to athletes reevaluating their athletic abilities, their role on the team, and their personal identity (Clement \& Shannon, 2011). 
There are a handful of mediators that influence an athlete's psychological response to injury, which includes: history of injury, severity and type of injury, personality, pain tolerance, athletic identity, coping skills, and history of stressors (Wiese-Bjornstal, Smith, Shaffer, \& Morrey, 1998). These mediators, the athlete's psychological response, and the environment surrounding the athlete, all come together to establish the athlete's way of coping. Coping consists of a two-step process of appraisal, which involves a primary appraisal and a secondary appraisal. Walker et al. (2007) stated, "Cognitive appraisals are processes through which a potentially stressful situation is assessed as being stressful and the individual's evaluation of the extent of that stress." (p. 175). Athletes examine what is at risk in his or her situation while in the primary appraisal stage (Wheeler, 2007). Some examples of this thought process could include an athlete's fear of losing playing time, fear of losing a scholarship, worry of financial costs of injury, and the distress of being unable to play the sport he or she enjoys. Each athlete will appraise his or her injury differently.

During the secondary appraisal, an athlete will ask if he or she has control over any aspect of the situation, and if the situation can be changed to make things less stressful or threatening. The athlete will also consider whether he or she can handle the emotions that come with the overall response to the injury (Wheeler, 2007). The athlete's answers will determine the type of coping that is most beneficial for the particular situation. The more an athlete utilizes proper coping methods, the better chance he or she will maintain a healthy state in regard to his or her mental health. This two-step appraisal process is something that occurs naturally with each person who deals with any kind of 
stress, major or minor, however it is important to recognize the way an athlete reacts to the stress of an injury.

\section{$\underline{\text { Social Support }}$}

Social support is the presence of others in an athlete's life who value and care about the athlete, and a support system upon which he or she can rely. Some examples of social support include family, friends, coaches, sports medicine staff, and teammate support (Andersen \& Williams, 1988). Social support exists in four different forms, including emotional support, instrumental support, informational support, and appraisal support. Emotional support includes qualities of empathy, trust, and love. Instrumental social support is the act of providing helpful services to another person, such as driving someone to the clinic. Informational social support involves sharing information, suggestions or advice; for example, an athletic trainer provides informational social support when he or she informs an athlete about his or her injury, and advises how to treat the injury and what to expect during recovery. Lastly, appraisal social support provides feedback to assist the development self-assessment of the stressful situation (Wheeler, 2007).

The different forms of social support are known to be helpful with coping during specific stages of injury. For example, directly after injury and throughout the injury period, emotional social support has been the most effective form of support for athletes. While emotional social support is crucial with the stress management of an injured athlete, athletes reported to prefer informational social support later in the injury process once they have accepted the injury and are focused on working toward recovery (Yang, Peek-Asa, Lowe, Heiden, \& Foster, 2010). 
Social support has been found to have a protective effect on mood, overall wellbeing, and the physical function of the body (Wheeler, 2007). The Stress and Coping Perspective, which is the most influential theoretical perspective on social support, promotes this concept of a protective effect (Lakey \& Cohen, 2000). Lakey and Cohen (2000) present the following hypothesis about The Stress and Coping Perspective, "support reduces the effects of stressful life events on health through either the supportive actions of others or belief that support is available." (p.30). Supportive actions can act as a stress buffer by enhancing the coping performance in the individual experiencing the stressor. This perspective also theorizes that the perceptions of available social support lead to appraising threatening situations as less stressful (Lakey \& Cohen, 2000). This decrease in distress includes the reduction of low self-esteem and depression (Baumesiter \& Leary, 1995).

Athletes are involved in many social networks because of their high involvement in university athletics and academics. Many athletes have teammates, friends, families and/or class peers whom they could consider their sources of social support. The general public might expect the average athlete to have this type of social support; however, the athlete's perception of the support—as well as the quality of support—can be lacking. The extent of this lack of support may be dependent on the dynamics of the team and the athlete, as well as the athlete's mood and attitude at times during the injury/recovery period. It is not uncommon for an athlete to suddenly feel a lack of team support from coaches and teammates after an athletic injury. Many athletes will report they are feeling as if they are letting their teammates down, which may cause the athletes to pull away and isolate themselves from the team. This can become a concern, given the significance 
of the psychological response to injury, and the importance of social support for the protective effects on athletes' health.

\section{$\underline{\text { Depression }}$}

Depression in young, elite athletes has become a greater concern as demands of competition continue to increase. The National Institute of Mental Health (NIMH) (2012) defines depression as, “a common but serious mental illness typically marked by sad or anxious feelings. Untreated depression lasts for a long time, interferes with day-to-day activities, and is much more than just being 'a little down' or 'feeling blue.'” (p. 2). While depression is becoming better understood as an illness, depression symptomatology is something that can be down-played and misunderstood. Depression symptomatology is simply the presence of depression symptoms without a formal diagnosis of depression. Although these symptoms may not be significant enough or experienced long enough for a formal diagnosis, athletes should be aware of the seriousness of these symptoms and that it is not something that should be overlooked or ignored. The symptoms of depression can arise from a variety of sources. If athletes are able to acknowledge their symptoms, they may be able to identify these sources, and treat/manage them appropriately.

Athletes are at risk of mental illness simply due to their lifestyle, which can include the following risk factors: overtraining, travel demands, lack of sleep, stress, loss of activity from injury, and high expectations to perform academically and athletically (Etzel, 2006). In addition to these risk factors, the increased stress associated with an injury and recovery creates an even greater risk of depression. There are specific profiles that stand out with regard to risk of depression, such as a family history of depression, 
personal history of other mental illness (anxiety, eating disorder, post-traumatic stress disorder), low self-esteem, self- criticism, and being involved in traumatic or stressful events (Depression, n.d.).

Depression is known to be underreported by athletes due to the fear of judgment, embarrassment, and appearing weak (Gulliver, Griffiths, \& Christensen, 2012). Stigmatization of depression prevents individuals from seeking out the help they need and decreases their quality of life. This stigmatization can be reduced through future indepth education of athletes and athletic department staff, along with the facilitation of social support by athletic trainers, team physicians, and coaching staff. These efforts could increase athlete reporting and treatment adherence, as well as decrease the overall risk of depression in college athletes.

The National Collegiate Athletic Association (NCAA) has acknowledged the concern for college athletes' mental health by creating a manual specifically for mental health concerns, which includes information on common mental illnesses, management/treatment options, and resources for further access. The emphasis of proper coping skills should be prioritized for athletes who appear to be struggling mentally with the stressors of being an athlete. As depression symptomatology post injury becomes more clearly understood in the medical field, there is hope that additional resources will become available to athletes before an injury occurs, as well as during the injury/recovery process.

$\underline{\text { Purpose }}$

The purpose of this study was to examine the relationship between perceived levels of social support and depression symptomatology post injury in injured Division 1 
collegiate athletes. This relationship was examined in males and females, by sport, as well as in different kinds of injury (i.e., acute, chronic, etc.).

\section{$\underline{\text { Significance of Study }}$}

Research is beginning to examine the significance of coping in athletes in regard to their injuries. Many studies have focused on the influence of coping resources on rehabilitation adherence and injury recovery in athletes. The current study focused on athlete's amount of depression symptomatology after injury as well as the amount of social support experienced during the injury/recovery period. This study was structured in a mixed methods approach, which allowed the researcher to gain a better understanding of the influence social support has on depression symptomatology post injury. Since the psychological response to injury is so complex, it was beneficial to use both quantitative and qualitative methods. This study hoped to uncover data to support the need for a greater emphasis on mental health in sports medicine care. Organizations such as the NCAA are currently making efforts to recognize mental health illnesses in athletes that normally may be undetected, and to develop action plans to allow sports medicine departments to improve the management of these illnesses.

Hypothesis

It is hypothesized that there is an inverse relationship between perceived levels of social support and degree of depression symptomatology. More specifically, it was hypothesized that there is an inverse relationship between perceived amounts of social support and degree of depression symptomatology as well as perceived satisfaction of social support and degree of depression symptomatology. 


\section{$\underline{\text { Definition of Terms }}$}

1. Injury: any damage caused to the body during athletic participation that requires medical attention and restricts an athlete from future participation in a practice or game/event for 1 or more days beyond the day of injury (Yang et al., 2010).

2. Depression: "a common but serious mental illness typically marked by sad or anxious feelings. Untreated depression lasts for a long time, interferes with day-to-day activities, and is much more than just being 'a little down' or 'feeling blue"' (National Institute of Mental Health, 2012, p. 2).

3. Depression symptomatology: the presence of depression symptoms without a formal diagnosis of depression.

4. Mood: a cognitive origin that is usually long term and has no specific cause of the feelings experienced (Walker et al., 2007).

4. Emotion: a cognitive origin that has a short-term effect and is easily linked to the source of the affected state (Walker et al., 2007).

5. Social support: the presence of others in an athlete's life who value and care about the athlete, and a support system upon which he or she can rely. Some examples of social support include family, friends, coaches, sports medicine staff, and teammate support (Andersen \& Williams, 1988).

\section{$\underline{\text { Delimitations and Limitations }}$}

This study was delimited to college-aged athletes attending Portland State University (PSU). The study included athletes from all PSU sports teams. After the surveys were completed, the interviews were delimited to injured athletes. All PSU athletes were eligible for participation in the survey portion of the study in order to have 
access to a greater variety of injuries and personalities. Because men and women are known to have different modes of processing stress, including both sexes was important.

\section{$\underline{\text { Assumptions }}$}

It is assumed that the participants all responded truthfully on all questionnaires and in all interviews. To encourage honest responses, the participants were reminded that all responses remained confidential and were anonymous. 


\section{Chapter 2}

\section{Review of Literature}

\section{$\underline{\text { Psychological Response to Athletic Injury }}$}

An injury is defined as any injury reported to a medical provider that causes full restriction from participation for 1 or more days (Yang et al., 2010; Smith et al., 1993). When an athlete experiences an injury, his or her body will begin to undergo a number of changes, which is known as the physiological and psychological responses to injury (Roh \& Perna, 2000). The psychological response to injury that many athletes experience can include: increased tension, anger, depression, anxiety, fear, reduced vigor, emotional disturbance, and low self-esteem (Mainwaring, Bisschop, Comper, Richards, \& Hutchison, 2010; Yang et al., 2010; Clement \& Shannon, 2011; Roh \& Perna, 2000; Leddy, Lambert, \& Ogles, 1994; Quinn \& Fallon, 1998).

Many theoretical constructs have been used to understand the complex, interactional nature of the psychological response to injury. While there are various theories in the literature, there are two that are most strongly applied and studied. The first is the cognitive appraisal model, which is one of the most popular frameworks applied in clinical and stress-related psychology literature. The cognitive appraisal model proposes that cognitive appraisals determine the extent of stress and threat a stressor provides to an individual (Walker et al., 2007; Hagger, Chatzisarantis, Griffin, \& Thatcher, 2005; Roh \& Perna, 2000; Wiese-Bjornstal et al., 1998; Brewer, Linder, \& Phelps, 1995; Tracey, 2003; Wheeler, 2007; Quinn \& Fallon, 1998). The appraisals also influence the manner in which someone will cope with a situation (Walker et al., 2007; Wiese-Bjornstal et al., 1998). 
Wiese-Bjornstal, Smith, and LaMott (1995) and Wiese-Bjornastal et al. (1998) were the first to propose the model of injury response. The interactional model specifically focuses on key aspects that mediate the appraisal process such as the characteristics of the injury, the sport specific situational factors, personal factors, and sports medicine staff interactions (Wiese-Bjornstal et al., 1998; Walker et al., 2007). Tracey (2003) includes a visual figure, "Figure 1. Integrated model depicting the psychological response to sport injury and rehabilitation process" (Figure 1), which provides a more detailed description and breakdown of the psychological response to injury (p. 281). A number of studies have found that the most influential mediators of the appraisal process are coping behaviors and social support resources (Roh \& Perna, 2000; Tracey, 2003; Walker et al., 2007; Yang et al., 2010). Smith et al. (1993) also discovered that severity of injury is a key moderator of the psychological response. This integrative model concludes that cognitive appraisals impact emotions that in turn affect behaviors (Walker et al., 2007).

Tracey (2003) discovered that her participants' cognitive appraisals strongly affected their emotional response to injury as well as the rehabilitation process. In her qualitative study, the participants reported that their negative thoughts made them feel depressed, which translated into their inability to remain optimistic and motivated during their rehabilitation phase (Tracey, 2003). These findings provide situational evidence of the importance of injury appraisals and their influence on the emotional and behavioral response in the rehabilitation setting. 


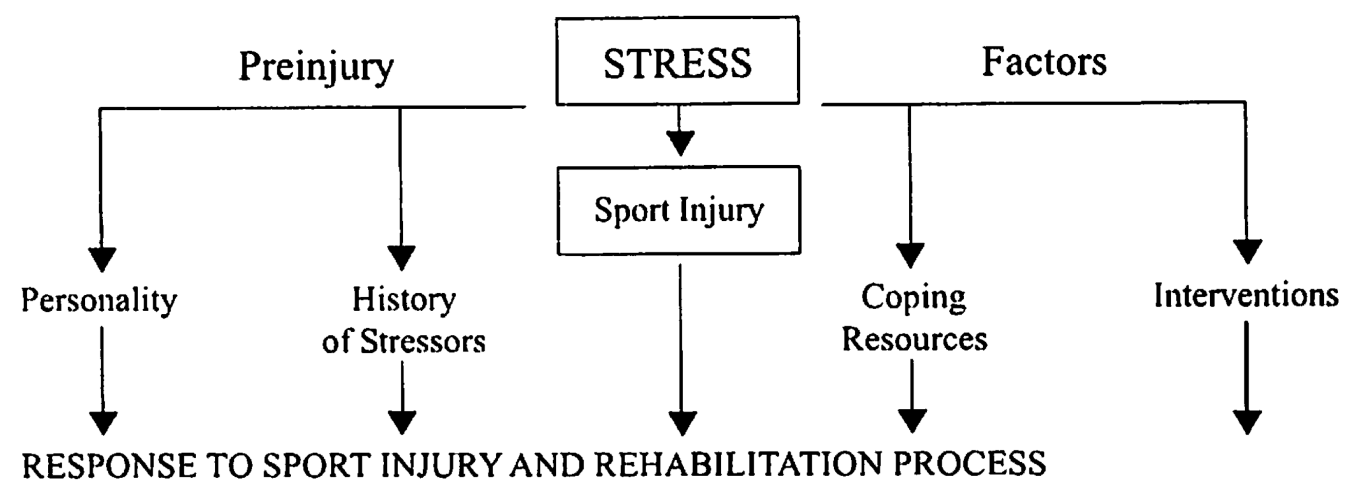

Personal Factors

Situational Factors

\begin{tabular}{|c|c|c|}
\hline $\begin{array}{l}\text { Injury } \\
\text { History } \\
\text { Scverity } \\
\text { Type } \\
\text { Perceived cause } \\
\text { Recovery status } \\
\text { Individual Differences } \\
\text { Psychological } \\
\text { personality } \\
\text { self-perceptions } \\
\text { self-motivation } \\
\text { motivational orientation } \\
\text { pain tolerance } \\
\text { athletic intensity } \\
\text { coping skills } \\
\text { history of stressors } \\
\text { mood states } \\
\text { Demographics } \\
\text { gender, age, ethnicity } \\
\text { socioeconomic status } \\
\text { prior sport experience } \\
\text { Physical } \\
\text { use of ergogenic aids } \\
\text { disordered eating }\end{array}$ & $\begin{array}{l}\text { COGNITIVE } \\
\text { APPRAISAL } \\
\text { Goal adjustment } \\
\text { Rate of perceived } \\
\text { recovery } \\
\text { Self-perceptions } \\
\text { Belief and attributions } \\
\text { Sense of loss or grief } \\
\text { Cognitive coping }\end{array}$ & $\begin{array}{l}\text { Sport } \\
\text { Type } \\
\text { Level of participation } \\
\text { Time in season } \\
\text { Playing status } \\
\text { Practice vs. game } \\
\text { Social } \\
\text { Teammate influence } \\
\text { Coach influence } \\
\text { Family dynamics } \\
\text { Sports medicine team } \\
\text { influences } \\
\text { Social support } \\
\text { provision } \\
\text { Sport ethic/philosophy } \\
\text { Environment } \\
\text { Rehabilitation environ- } \\
\text { ment } \\
\text { Accessibility to } \\
\text { rehabilitation }\end{array}$ \\
\hline
\end{tabular}

Figure 1. Integrated model depicting the psychological response to sport injury and rehabilitation process.

Figure 1. Integrated model depicting the psychological response to sport injury and rehabilitation process 
Self-regulation theory is also being used in injury/illness research to understand the psychological processes. Hagger et al., (2005) notes the theory as "if the illness or condition is represented as sufficiently threatening by an individual, he or she will be compelled to search for appropriate coping procedures to ameliorate the perceived threat" (p. 2347). It is proposed that coping acts a significant mediator for the emotional and cognitive responses that follow an injury/illness. Both of these theoretical frameworks underscore the importance of proper coping following a stressful event such as an athletic injury.

Past research has prioritized a stronger focus on injury prevention and recovery than psychological stresses of injury and the concerns that result from these stresses (Tracey, 2003; Roh \& Perna, 2000). For example, the NCAA supports injury surveillance through its Injury Surveillance System (ISS), which tracks athletic injury data for all NCAA collegiate sports. This surveillance system provides a substantial amount of data for the purpose of finding more information regarding the prevention and recovery of injury (Hootman et al., 2007). While this injury surveillance is an important resource for athletic injury research, there is hope to use this system congruently with research focusing on the psychological aspects of athletic injury.

Research regarding the psychological concerns of an injury is slowly developing, however the literature is not as strong or focused as it needs to be. There are many studies examining psychological responses to injury; however, they focus strongly on the rehabilitation and recovery processes. Therefore, this study was designed to provide support for the current research regarding the psychological response to injury; it was 
also designed to uncover new information that would support the athletes' mental health and overall well-being during the injury and recovery processes.

\section{$\underline{\text { Social Support }}$}

Social support is a construct associated with mental health, stress, and managing individuals' overall well-being. Shumaker and Brownell (1984) define social support as "an exchange of resources between at least two individuals perceived by the provider or the recipient to be intended to enhance the well-being of the recipient" (p. 13). There is a significant body of research supporting social support as an important factor in the facilitation of injury/illness recovery (Yang et al., 2010; Clement \& Shannon, 2011; Roh \& Perna, 2000; Ford \& Gordon, 1999). Findings have also been reported to suggest that positive social support could be protective in reducing distress in injured individuals as well as enhancing motivation in these individuals during the rehabilitation process (Yang et al., 2010; Clement \& Shannon, 2011; Roh \& Perna, 2000; Ford \& Gordon, 1999).

Two hypotheses have been proposed to explain how social support influences the rehabilitation process of injured individuals: the buffering hypothesis and the direct-effect hypothesis (Clement \& Shannon, 2011). Clement \& Shannon (2011) describes the buffering hypothesis and states, social support "moderates the harmful effects of stress and indirectly affects injured athletes' health and well-being" (p. 458, as cited in Hardy, Richman, \& Rosenfeld, 1991). On the contrary, Clement \& Shannon (2011) described the direct-effect hypothesis, stating "the amount and effectiveness of social support influences psychological and physical well-being" (p. 458, cited by Hardy, Richman, \& Rosenfeld, 1991). This is an important distinction because many studies measure social support in different ways. Many studies measure social support as the total number of 
perceived individuals a person can rely on as well as the perceived quality of support during stressful times (Sarason et al., 1983; Sarason et al., 1987; Yang et al., 2010; Rosenfeld, Richman, \& Hardy, 1989; Clement \& Shannon, 2011;).

Tracey (2003) provided findings to show how important the type of social support is at different periods of the injury process. For example, she found that participants reported the medical staff as an important source of their support throughout the entire injury process (Tracey, 2003). Other studies also found that injured athletes had a very high amount of perceived support from sports medicine staff (Yang et al., 2010; Clement $\&$ Shannon, 2011). There were a large number of participants reporting the lack of desired support from the coaching staff for a variety of reasons. This was not confirmed by Yang et al. (2010) due to finding that injured athletes had an increased desire of support from coaches compared to their pre-injury support.

Research regarding social support and athletic injury is accumulating, however the sports medicine teams and coaches who surround the athlete need to become aware of these important findings. This study was designed to provide additional information regarding the impact of social support on injured athletes' mental health.

\section{Depression}

Depression in college athletes is becoming a greater concern as the demands of competition continue to rise. The study of depression among college athletes as a health issue is in its infancy. It is generally understood that athletes' high levels of participation in physical activity can reduce the risk of depression (Gulliver et al., 2012). College athletes are at risk of mental illness simply due to their lifestyle, which can include the following risk factors: overtraining, travel demands, lack of sleep, stress, loss of activity 
from injury, and high expectations to perform academically and athletically (Etzel, 2006). Armstrong \& Oomen-Early (2009) found “...social connectedness, gender, sleep, and self-esteem were significant in predicting depression" (P. 253).

Depression is known to be underreported by many different types of athletes due to the fear of judgment, embarrassment, and appearing weak (Gulliver et al., 2012; Yang et al., 2007). This stigmatization of depression can prevent individuals from seeking out the help they need and decrease their quality of life. The socialization of sport over many decades and throughout many cultures affects athletes mentally and physically more than ever. Wiese-Bjornstal et al. (1998) describes interviews performed on former male athletes to identify internal and external pressures that come from this sport socialization (as cited in Messer, 1992). For example, male athletes report that their masculinity is threatened and judged through external pressures from coaches, teammates, and fans when refusing to play while hurt (as cited in Messner, 1992). Female athletes also experience these pressures and expectations and will continue be challenged about their "strength" and "toughness" (Wiese-Bjornstal et al., 1998).

Post injury depression or depression symptomatology is an ongoing topic of research that continues to inform developments and advancements in sports medicine. Smith, et al. (1993) found that the severity of injury was most predictive of post injury depression. Armstrong \& Oomen-Early (2009) reported, “...people who are more socially connected report less psychological distress including depression and low selfesteem, than people who are less connected" (p.521). These findings relate to the social support literature, confirming the importance of social support in all athletes, but more specifically injured athletes, to ensure a healthy mental status. While many of these 
findings are influential and significant, there is still a substantial lack of research and epidemiological data regarding the mental health of college athletes (Yang, et al, 2007). It is hopeful that there will be an increased focus on college athletes' mental health in future research to assist in the development of mental health policy and interventions.

\section{Methods of Measurement}

Past research has used a wide variety of tools to measure the variables previously described (e.g., psychological response to injury, social support, depression symptomatology, etc.). The current study used a mixed-methods design to incorporate detailed subjective data obtained from a qualitative approach with the data provided by the quantitative approach. Past research has recommended the need for qualitative methods, specifically interviews, for injured individuals and the complex details that come with being injured (Tracey, 2003; Wiese-Bjornstal et al., 1998; Clement \& Shannon, 2011). To gain a better understanding of social support and the strong role social support has on the injury/recovery process, qualitative methodology should be considered (Clement \& Shannon, 2011).

The current study measured depression symptomatology with the Center for Epidemiological Studies Depression Scale Revised (CESD-R), which has been used in a number of studies. The CESD-R was originally developed for a National Institute of Mental Health study for adults to measure depressive symptoms (Yang et al., 2007; Armstrong \& Oomen-Early, 2009). The scale was validated for college student populations and is now available for general public use as well as research purposes.

The current study measured social support with the Social Support Questionnaire 6- a modified version of the Social Support Questionnaire developed by Sarason et al. 
(1983). This shorter version has been validated in college student populations and continues to be used in the current literature (Yang et al., 2010). 


\section{Chapter 3}

\section{Methods}

\section{$\underline{\text { Subjects }}$}

The sample for this study was a convenience sample of about 245 student athletes from Portland State University (PSU). Athletes from all PSU sport teams were included to receive a greater variety of perspectives regarding psychological response to injury and social support. These sport teams included: basketball, volleyball, football, golf, softball, soccer, track and field/cross country, tennis, and cheerleading. Having all athletes included also increases statistical power.

Athletes were recruited via email and in-person by the student investigator. The student investigator met with available teams separately to follow up with athletes for further recruitment of participants. The team coaches were not present during this time. The athletic treatment center was also a location for in-person study recruitment. All participation was voluntary, and confidentiality of responses was assured. Any student athlete who was recovering from a concussion was excluded from the study. Since head injuries can result in cognitive impairments, the emotional state can be directly affected (Giza \& Hovda, 2001).

\section{Variables}

Measurements included demographic information, social support (Social Support Questionnaire 6, (SSQ6)), and depression symptomatology (The Center for Epidemiological Studies Depression Scale Revised, (CESD-R)). The measurements were obtained through a variety of surveys detailed below. A selection of the injured athletes also had the opportunity to participate in an interview with the investigator. The interview 
was semi-structured, focused on specific details regarding the athlete's experience being injured, psychological response to the injury, and opinions regarding his or her perceived social support.

$\underline{\text { Measurements }}$

Demographic Survey (Appendix A)

The demographic survey included questions regarding the following information: age, gender, sport, history of injury, history of depression and anxiety, academic standing, and amount of experience in sport. At the end of the survey there was an opportunity for the injured athlete to volunteer for an interview with the investigator at a future date determined by the athlete and the investigator. Not all interested injured athletes participated in the interview process due the investigator using a purposeful selection process to achieve relevant, non-repetitive information.

Social Support Questionnaire 6 (SSQ6) (Appendix B)

The SSQ6 (Sarason et al., 1987) was used to measure an athlete's perceived level of social support in his or her everyday life. The SSQ6 consists of 6 items that assess two aspects of social support, (1) the number of available individuals the person can turn to in a variety of situations, and (2) how satisfied the person is with the available support he or she currently has. The athlete identified which individuals would be available for each situation by using each person's initials, followed by rating the support on a scale from 1 (very dissatisfied) to 6 (very satisfied). After the completion of the questionnaire, the number of support personnel for each situation and satisfaction ratings were totaled and divided by 6 . This provided the SSQ Number Score (SSQN) and the SSQ Satisfaction 
Score (SSQS). Internal reliabilities for the SSQ6 have been reported as ranging from 0.93 to 0.96 (Sarason et al., 1990).

The Center for Epidemiological Studies Depression Scale Revised (CESD-R) (Appendix C)

The CESD-R (Eaton, Muntaner, Smith, Tien, \& Ybarra, 2004) is a 20-item scale that measures symptoms of depression from nine different categories, which have been determined by the American Psychiatric Association Diagnostic and Statistical Manual (About CESD-R, 2013). These categories include: sadness, loss of interest, appetite, sleep, thinking/concentrating, guilt, tired, movement, and suicidal ideation. The survey provided two to three statements that relate to each of these nine categories, and the athlete described his or her experience over the past week from a 5-point Likert scale: not at all or less than one day last week, 1-2 days last week, 3-4 days last week, 5-7 days last week, nearly every day for 2 weeks. Internal consistency for the CESD-R has been reported as ranging from $r=0.80-0.90$, test-retest reliability was reported as ranging from $\mathrm{r}=0.40-0.70$, and high sensitivity and specificity were reported for individuals with depression (Eaton et al., 2004).

Procedure

The subjects were initially approached via email by the student investigator. The student investigator provided details about the study in the email and explained what was required of the participants. Participants also received information regarding ethical considerations. If the participant had any questions or concerns before committing to study participation, he or she had the opportunity to talk to the student investigator. The participants met with the student investigator in-person to complete the informed consent 
form (Appendix E) and study materials, which included the three surveys (demographic survey, SSQ6, and CESD-R). Since the student investigator did not receive high numbers of participants from the email recruitment, the student investigator met with each team separately for further study recruitment.

The participants had an opportunity to request their survey results from the investigator after the completion of the study. Completed surveys were collected and placed in a manila envelope, which was stored in a locked file cabinet that was secured behind two locked doors. The investigator calculated scores and recorded them on a computer-based spreadsheet for data analysis.

The subjects participating in the voluntary interview arranged an appropriate time for an interview with the investigator. The subjects completed an additional informed consent form (Appendix F) specifically for the interview process, which also granted permission to record audio from the interview for future transcription. The athlete was informed of his or her ability to skip a topic/question if he or she was not comfortable discussing the information pursued during the interview. The athlete was also reminded of the option to opt out of the interview if he or she had the desire to do so during any point in the interview. The interview was semi-structured, facilitated by the interview guide attached in Appendix D. Each interview lasted for about 15-20 minutes.

\section{$\underline{\text { Statistical Analysis }}$}

Simple descriptive statistics were used to summarize levels of perceived social support and the extent of depressive symptomatology post injury. A Pearson ProductMoment correlation was also used to examine the relationship between social support satisfaction/amount of social support and depression symptomatology. 


\section{Chapter 4}

Results

\section{Characteristics of Participants}

A total of 115 PSU student athletes from all nine varsity sports participated in the survey portion of the study. One student athlete was excluded from the study because he/she was recovering from a concussion. There were 56 males $(48.7 \%)$ and 59 females $(51.3 \%)$. Football had the greatest representation (38.3\%), followed by soccer $(14.8 \%)$ and softball $(13.0 \%)$. The majority of the participants $(73.9 \%)$ reported to be non-injured at the time of survey participation. Of those who reported an injury, $46.7 \%$ reported an acute injury, 36.7\% reported a chronic injury, and 13.4\% reported experiencing both acute and chronic injuries at the time of the survey. A total of three injured PSU student athletes ( 1 male, 2 females) participated in the interview portion of the study; two athletes reported chronic injuries and one athlete reported two acute injuries that transitioned into chronic injuries.

\section{$\underline{\text { Social Support }}$}

The average amount of social support (SSQN) of the entire sample was $4.17 \pm 1.77$ (range: 1-9). The average social support satisfaction (SSQS) was 5.28 \pm 1.19 (range 0-6). The maximum number of social support sources allowed was nine, and the maximum social support satisfaction score allowed was 6 (very satisfied). Table 1 presents the averages and standard deviations for the amount of social support (SSQN), social support satisfaction (SSQS), and depression symptomatology scores (CESD-R) for the total sample as well as for each sex. Females appeared to have more social support sources as well as a higher social support satisfaction than males (Table 1). 
Table 1. Amount of social support (SSQN), social support satisfaction (SSQS), and depression symptomatology score (CESD-R).

\begin{tabular}{|c|c|c|c|}
\hline Sex & SSQN & SSQS & CESD-R \\
\hline Females $(\mathbf{n}=\mathbf{5 9})$ & $4.68 \pm 1.68$ & $5.42 \pm 0.89$ & $11.20 \pm 10.04$ \\
\hline Males $(\mathbf{n}=\mathbf{5 6})$ & $3.63 \pm 1.72$ & $5.13 \pm 1.43$ & $10.23 \pm 9.74$ \\
\hline Total $(\mathbf{n}=\mathbf{1 1 5})$ & $4.17 \pm 1.77$ & $5.28 \pm 1.19$ & $10.73 \pm 9.86$ \\
\hline
\end{tabular}

$($ mean $\pm \mathrm{sd})$

Non-injured student athletes appeared to have fewer social support sources as well as less social support satisfaction than injured student athletes. Of the injured athletes, those with a chronic injury reported more sources of social support $(5.06 \pm 1.51)$.

Student athletes with chronic injuries as well as student athletes with both chronic and acute injuries reported similar levels of social support satisfaction satisfaction (Table 2).

Table 2. Amount of social support (SSQN), social support satisfaction (SSQS), and depression symptomatology score (CESD-R).

\begin{tabular}{|c|c|c|c|}
\hline \multicolumn{1}{|c|}{ Status } & SSQN & SSQS & CESD-R \\
\hline Non-injured (n=85) & $3.99 \pm 1.73$ & $5.25 \pm 1.20$ & $9.27 \pm 8.44$ \\
\hline Injured (n=30) & $4.69 \pm 1.81$ & $5.36 \pm 1.16$ & $14.87 \pm 12.33$ \\
\hline Acute (n=14) & $4.69 \pm 2.13$ & $5.05 \pm 1.57$ & $14.64 \pm 11.28$ \\
\hline Chronic (n=11) & $5.06 \pm 1.51$ & $5.53 \pm 0.60$ & $13.73 \pm 12.40$ \\
\hline $\begin{array}{c}\text { Both acute and } \\
\text { chronic }(\mathbf{n}=\mathbf{4})\end{array}$ & $4.37 \pm 0.99$ & $5.83 \pm 0.34$ & $16.50 \pm 19.23$ \\
\hline
\end{tabular}

$($ mean $\pm \mathrm{sd})$

Sports team with the highest average number of social support sources included volleyball $(5.0 \pm 1.3)$, followed by women's basketball $(4.9 \pm 2.0)$. Sports with the lowest average number of social support sources included men's basketball $(3.2 \pm 1.3)$, followed by football $(3.7 \pm 1.8)$ (Figure 2$)$. The highest average social support satisfaction was 
reported by men's tennis (6), followed by track \& field/cross country (5.9). Football rated their social support satisfaction lowest (5.1), followed by softball (5.2) (Figure 3).

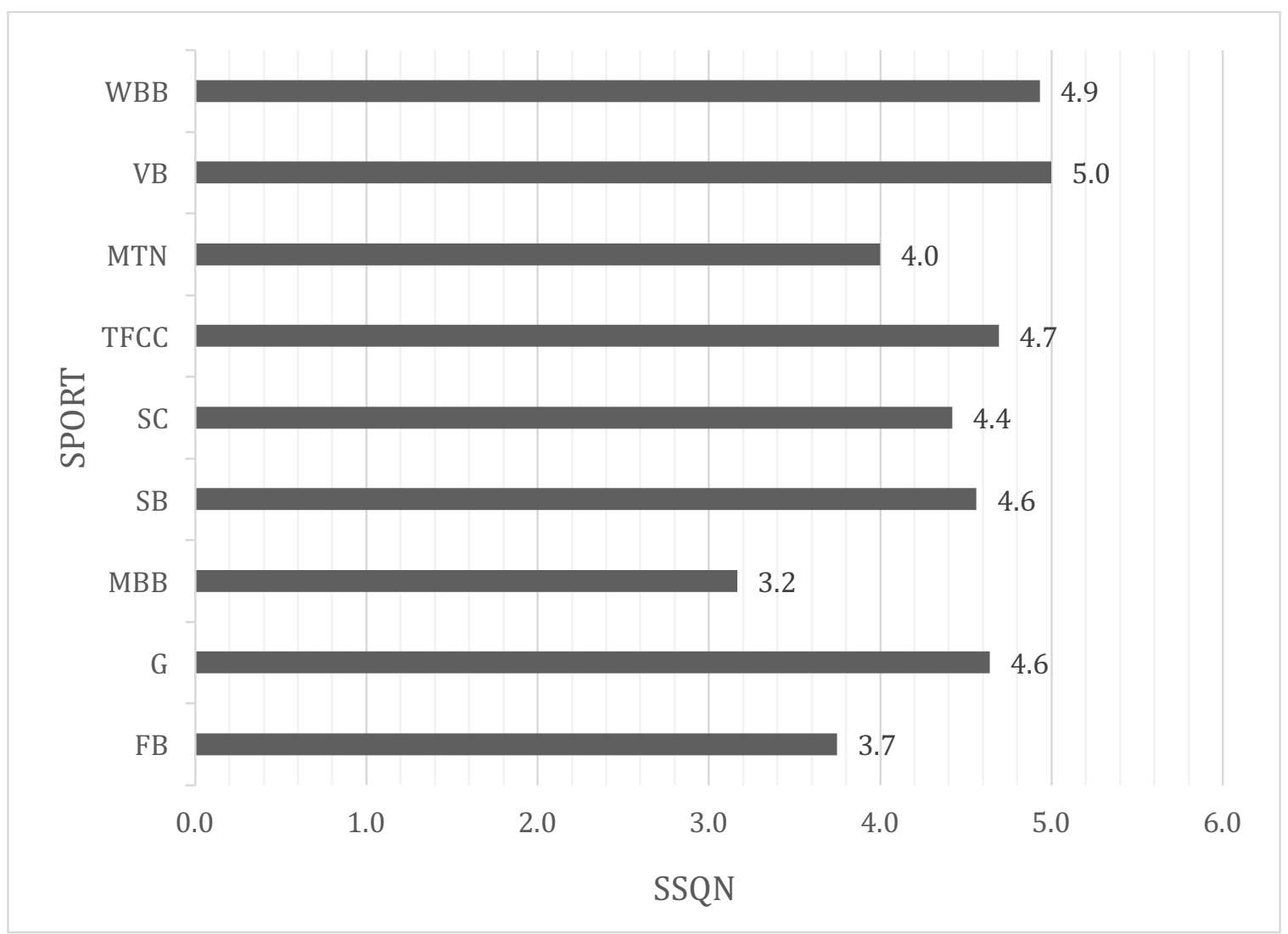

Figure 2. Average amount of social support (SSQN) reported by sport.

*Note: $\mathrm{WBB}=$ Women's Basketball $(\mathrm{n}=11), \mathrm{VB}=$ Volleyball $(\mathrm{n}=5), \mathrm{MTN}=$ Men's Tennis $(\mathrm{n}=1)$, TFCC $=$ Track and Field/Cross Country $(\mathrm{n}=6), \mathrm{SC}=$ Soccer $(\mathrm{n}=17)$, $\mathrm{SB}=$ Softball $(\mathrm{n}=15), \mathrm{MBB}=$ Men's Basketball $(\mathrm{n}=10), \mathrm{G}=$ Golf $(\mathrm{n}=6), \mathrm{FB}=$ Football $(\mathrm{n}=44)$. 


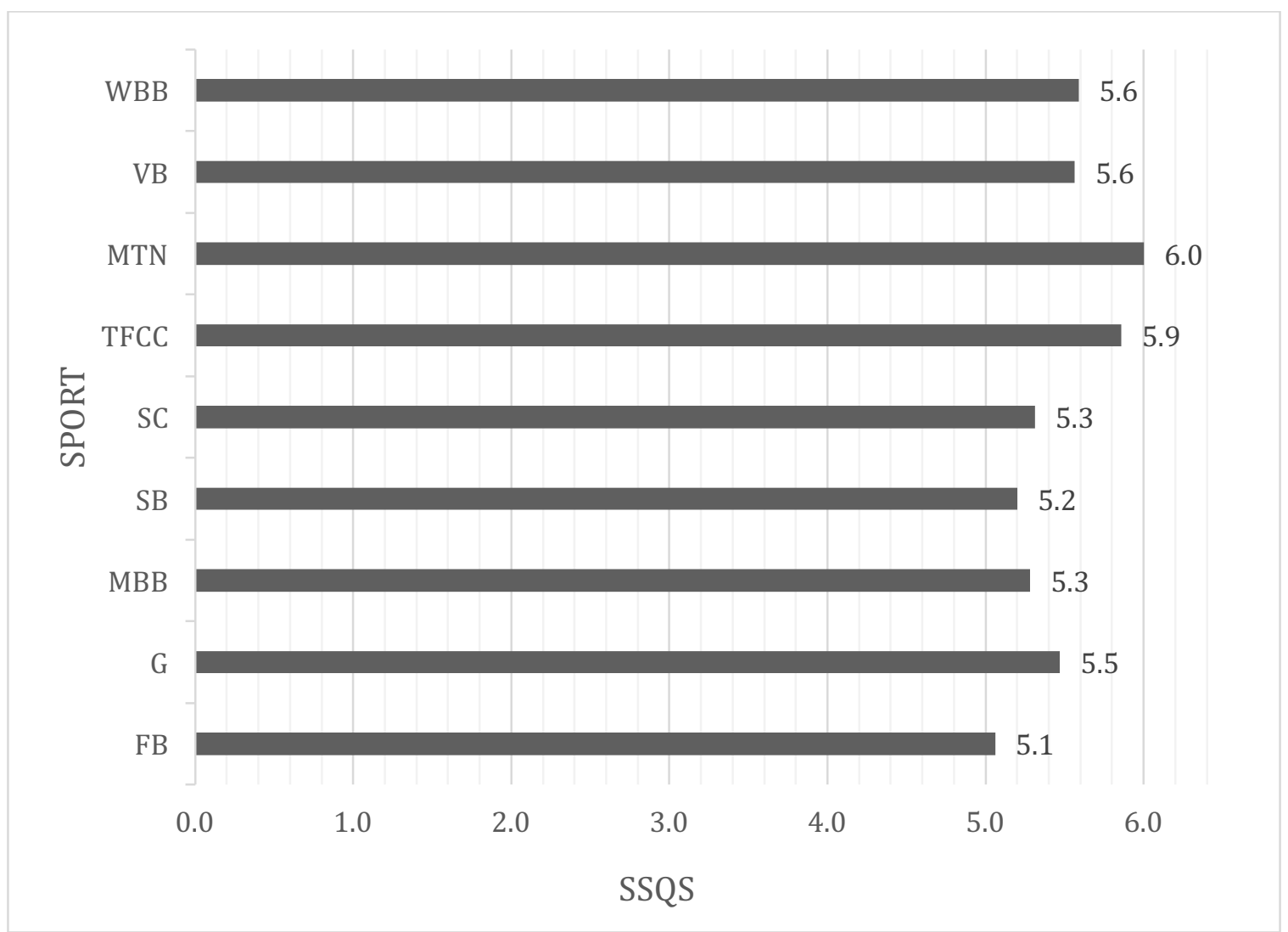

Figure 3. Average social support satisfaction (SSQS) reported by sport.

*Note: WBB=Women's Basketball $(\mathrm{n}=11), \mathrm{VB}=$ Volleyball $(\mathrm{n}=5), \mathrm{MTN}=$ Men's Tennis $(n=1)$, TFCC $=$ Track and Field/Cross Country $(n=6), S C=\operatorname{Soccer}(n=17)$, $\mathrm{SB}=$ Softball $(\mathrm{n}=15), \mathrm{MBB}=$ Men's Basketball $(\mathrm{n}=10), \mathrm{G}=\mathrm{Golf}(\mathrm{n}=6), \mathrm{FB}=$ Football $(n=44)$.

Figure 4 presents a breakdown of depressive symptom categories (CESD-R) and the social support satisfaction for each category. Category 1, which is defined as no clinical significance for depression (based on CESD-R responses), appeared to have the highest average level of social support satisfaction (5.4 \pm 1.2$)$. Category 5 , which is defined as meeting criteria for major depressive episode (based on CESD-R responses), had the lowest average level of social support satisfaction $(4.0 \pm 0)$. 


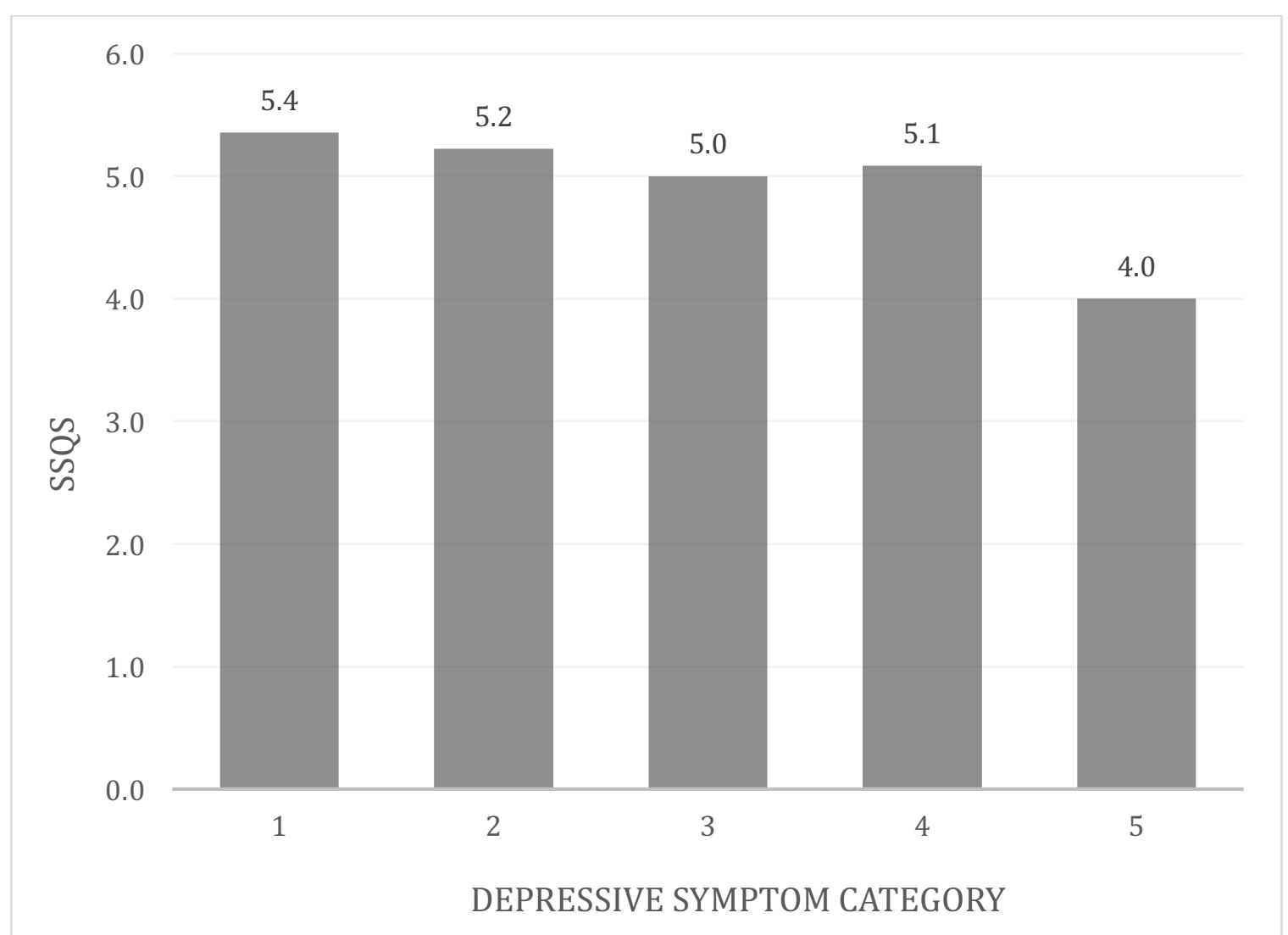

Figure 4. Average social support satisfaction (SSQS) reported by depressive symptom category (CESD-R).

*Note: Category 1 = No clinical significance for depression $(n=83)$; Category $2=$ Subthreshold depression symptoms $(n=28)$; Category 3 = Possible major depressive episode $(n=1)$; Category $4=$ Probable major depressive episode $(n=2)$; Category 5 = Meets criteria for major depressive episode $(n=1)$ (About CESD-R, 2013).

\section{Depression Symptomatology}

The average depression symptomatology score (CESD-R) for all participants was $10.73 \pm 9.86$. Females appeared to have a higher average depression symptomatology score $(11.20 \pm 10.04)$ than males $(10.23 \pm 9.74)$ (Table 1). Non-injured student athletes reported a lower average depression symptomatology score $(9.27 \pm 8.44)$ than injured student athletes $(14.87 \pm 12.33)$ (Table 2). Sports teams with the highest average depression symptomatology score were track \& field/cross country $(14.8 \pm 11.2)$ followed 
by softball (14.0 \pm 11.6$)$. Men's tennis had the lowest average depression symptomatology score $(6.0 \pm 0)$ followed by golf $(7.8 \pm 8.4)$ (Figure 5$)$.

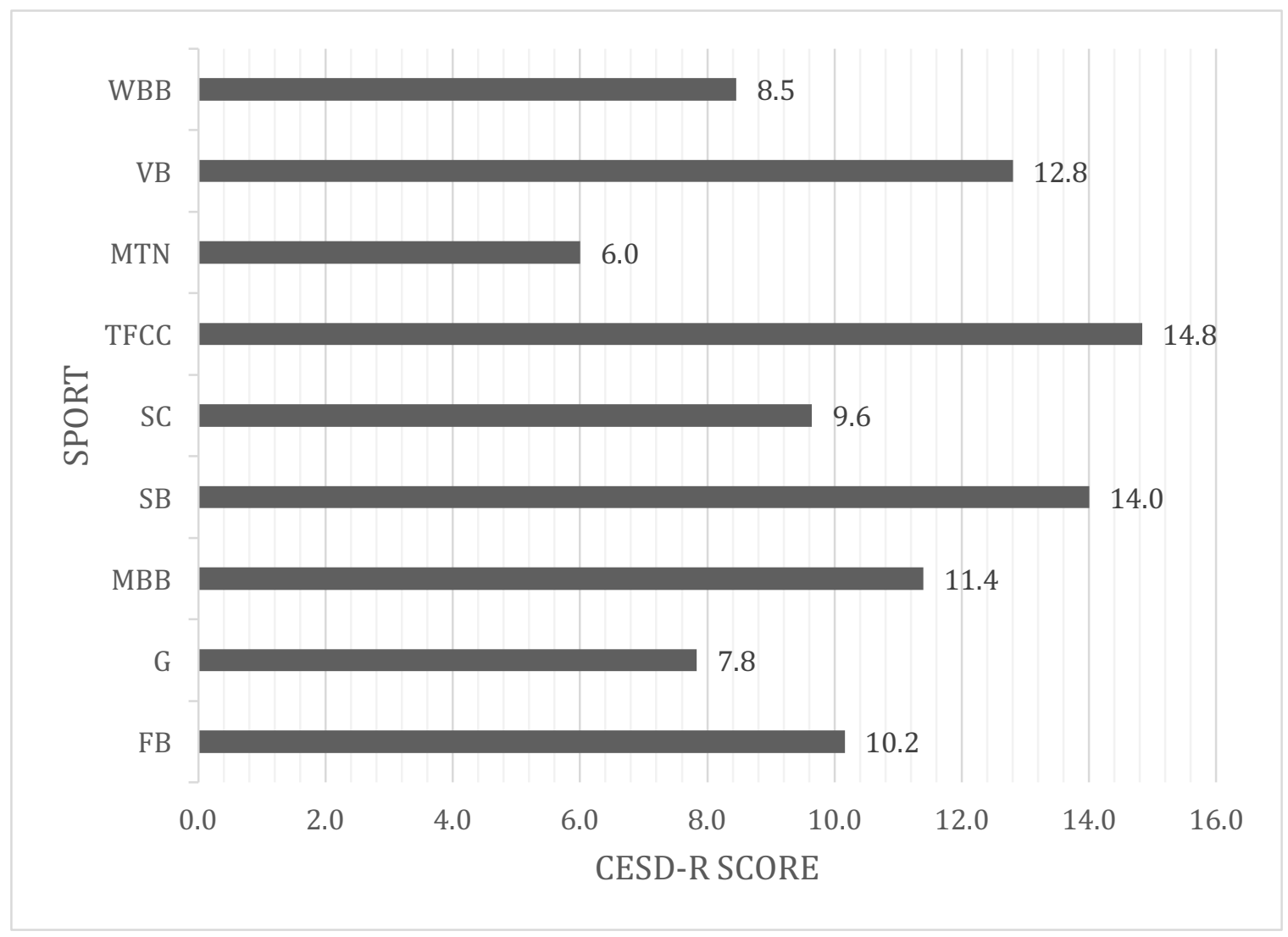

Figure 5. Average depression symptomatology score (CESD-R) reported by sport. *Note: $\mathrm{WBB}=$ Women's Basketball $(\mathrm{n}=11), \mathrm{VB}=$ Volleyball $(\mathrm{n}=5), \mathrm{MTN}=$ Men's Tennis $(n=1), T F C C=$ Track and Field/Cross Country $(n=6), S C=\operatorname{Soccer}(n=17)$, $\mathrm{SB}=$ Softball $(\mathrm{n}=15), \mathrm{MBB}=$ Men's Basketball $(\mathrm{n}=10), \mathrm{G}=\mathrm{Golf}(\mathrm{n}=6), \mathrm{FB}=$ Football $(n=44)$.

Figure 6 shows the total number of athletes in each depressive symptom categories (CESD-R). Of the entire sample, 72.2 percent met the criteria for Category 1no clinical significance for depression, while 27.8 percent met the criteria for a depressive symptom concern (Figure 6). 


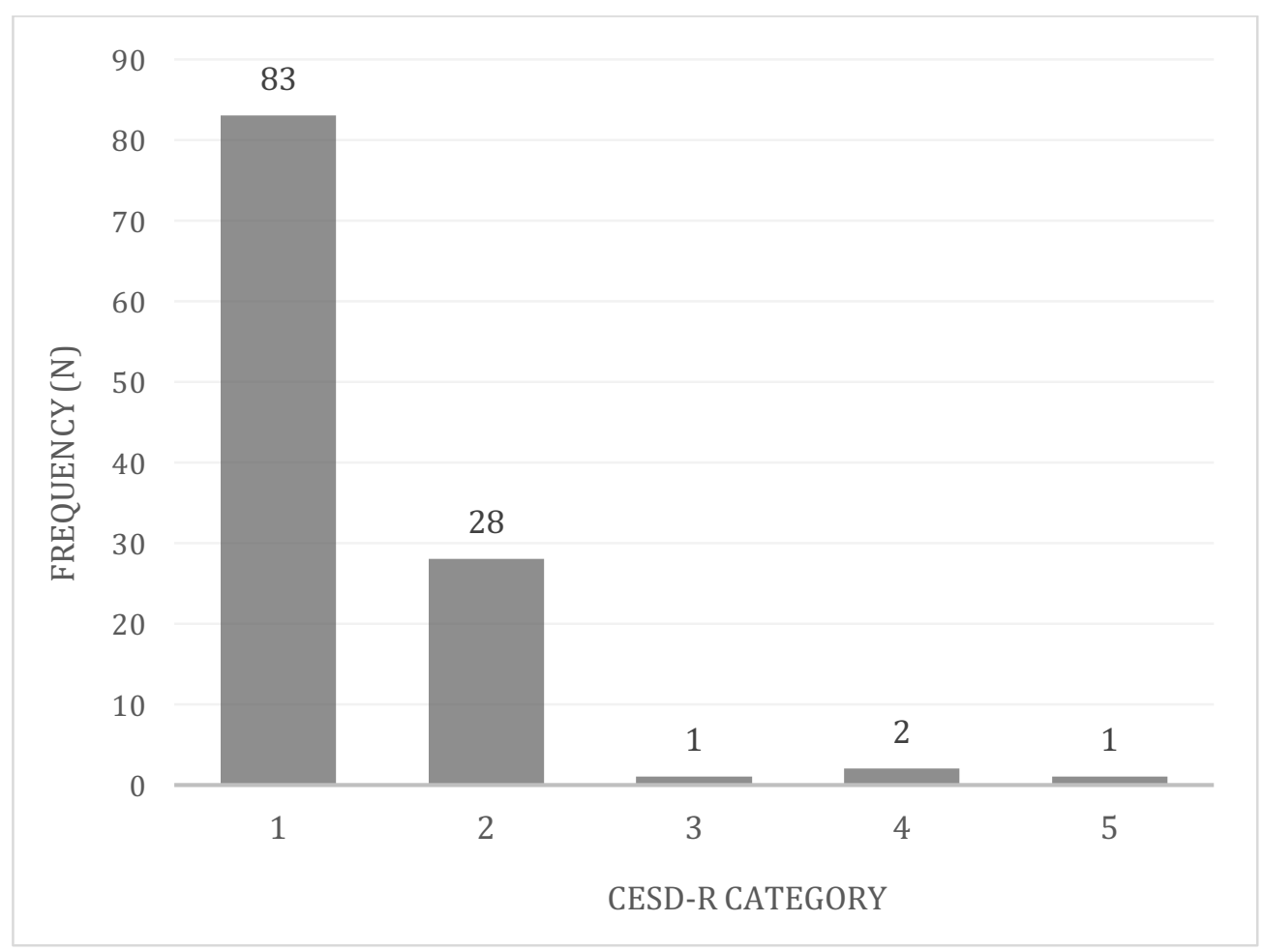

Figure 6. Total number of athletes in each depressive symptom category (CESD-R).

*Note: Category $1=$ No clinical significance for depression $(\mathrm{n}=83)$; Category $2=$ Subthreshold depression symptoms $(\mathrm{n}=28)$; Category $3=$ Possible major depressive episode $(\mathrm{n}=1)$; Category $4=$ Probable major depressive episode $(\mathrm{n}=2)$; Category $5=$ Meets criteria for major depressive episode $(n=1)$ (About CESD-R, 2013).

Relationship between Social Support and Depression Symptomatology

A Pearson Product-Moment correlation was used to examine the relationship between social support satisfaction/amount of social support and depression symptomatology. Statistically significant relationships were found between the satisfaction of social support and depression symptomatology in student athletes with a chronic injury as well as non-injured student athletes. A statistically significant relationship was also noted between the amount of social support and depression symptomatology in student athletes who experience both acute and chronic injuries at the same time (Table 3). No statistically significant relationships were noted between the 
amount of social support and depression symptomatology for the total study sample as

well as for male and female subgroups (Table 4).

Table 3. Pearson correlations for social support satisfaction (SSQS) vs. depression symptomatology score (CESD-R) and amount of social support (SSQN) vs. depression symptomatology score (CESD-R) in injured and non-injured athletes.

\begin{tabular}{|c|c|c|}
\hline \multicolumn{1}{|c|}{ Status } & SSQS vs CESD-R & SSQN vs CESD-R \\
\hline Non Injured (n=85) & $-0.25^{*}$ & 0.03 \\
\hline Injured $(\mathbf{n}=\mathbf{3 0})$ & -0.05 & -0.10 \\
\hline Acute $(\mathbf{n}=\mathbf{1 4})$ & 0.12 & 0.02 \\
\hline Chronic $(\mathbf{n = 1 1 )}$ & $-0.78^{*}$ & 0.01 \\
\hline Both $(\mathbf{n}=\mathbf{4})$ & 0.19 & $-0.77^{*}$ \\
\hline
\end{tabular}

${ }^{*} \mathrm{p} \leq 0.05$

Table 4. Pearson correlations for social support satisfaction (SSQS) vs. depression symptomatology score (CESD-R) and amount of social support (SSQN) vs. depression symptomatology score (CESD-R) in males and females.

\begin{tabular}{|l|c|c|}
\hline \multicolumn{1}{|c|}{ Sex } & SSQN vs CESD-R & SSQS vs CESD-R \\
\hline Females $(\mathbf{n}=\mathbf{5 9})$ & -0.06 & -0.16 \\
\hline Males $(\mathbf{n}=\mathbf{5 6})$ & 0.09 & -0.19 \\
\hline Total $(\mathbf{n}=\mathbf{1 1 5})$ & 0.03 & -0.16 \\
\hline
\end{tabular}




\section{Chapter 5}

Discussion

This study was designed to examine the relationship between social support and depression symptomatology post injury in Division 1 collegiate student athletes. Prior to this study, only a few studies have examined (1) how the amount of social support and social support satisfaction changes before and after injury (Yang et al., 2010), (2) injured student athletes' perceptions of satisfaction, availability, and contribution of social support (Clement \& Shannon, 2011), and (3) the emotional adjustment to athletic injury (Brewer et al., 1995). The current study builds upon the results of previous studies. This study found that injured student athletes reported higher amounts of social support and higher levels of social support satisfaction than their non-injured peers. These results support those of Yang et al. (2010), who found that athletes had a higher post injury satisfaction of their social support (compared to baseline).

The current study included one-on-one interviews with selected participants in an effort to gather more detailed information regarding social support and depression symptomatology in injured athletes. The interviews found that social support from a coach is helpful; however, it does not appear to be the most desired form of social support. One student athlete expressed that her coach did go out of his way to ask her how she was doing mentally during the period of being unable to participate in her sport because of her injury. She later said, "It's harder for me to open up to my coach. I definitely want to be strong. I think if I did open up and break down in front of him, it would be fine, but I try to avoid that... appearing strong is important to me." Tracey 
(2003) also found that her participants reported a "clear lack of a desire to seek social support from the coach" (p. 290).

Another student athlete described a clear lack of support from her coach, which she explained was one of the difficult parts of being injured. The student athlete described her experience as, "It just felt like I was just a body...like 'let's put you over here on this bike until you can come back and actually do something'." She later explained how her coach would never ask how she was feeling or how she was handling the injury process. She expressed that some of depression symptomatology was due to the lack of support and added stress from her coach.

In the current study, females reported a greater number of social support sources as well as a higher level of social support satisfaction compared to males. Gulliver et al. (2012) reported that males found it more difficult to seek help due to the fear of appearing weak, as well as struggling with expressing their feelings, due to a lack of intrapersonal articulation of their feelings. Yang et al. (2010) confirmed these findings; they indicated that females reported greater post injury social support satisfaction compared to males. Yang et al. (2007), and Yang et al. (2010) both noted that females generally have better help-seeking behaviors than males.

In interviews conducted in the current study it was found that the females appeared to cope with their injuries by talking to family and friends. The females reported that the most helpful part of their social support was someone listening to them, and having received encouragement or advice from someone who had experienced a similar injury/situation. Clement and Shannon (2011) reported similar findings, stating that their participants were most satisfied with listening support. In the current study, the 
male interview participant explained that talking to people was not his preferred way of coping, as he said “definitely not talking to people, I won't reveal it (his feelings)." The male student athlete later elaborated about a strong support system consisting of his parents, teammates, coach, and athletic trainer. He described his social support as people "being there" for him (parents, friends, teammates, and coach), working with him (coach and athletic trainer), and simply caring about him and his well-being.

Since males have reported a lower average number of social support sources and lower social support satisfaction in the current study (Table 1), it was anticipated that the male sports teams would report both social support indicators lower than female sports teams. In the current study, men's basketball reported the lowest average number of social support sources, followed by football and men's tennis. Since these three sports are comprised of only male student athletes (compared to track \& field/cross country consisting of males and females), this distribution of data shows that the results are consistent across several different categorizations of groups.

The current study also found that females reported a higher average depression symptomatology (CESD-R) score compared to males. These findings are consistent with those of Yang et al. (2007) who found that "female gender is associated with an increased risk of experiencing symptoms of depression" (p. 484). Interviews conducted in the current study revealed common symptoms reported by the female student athletes and the factors that specifically caused these symptoms. One of the participants said, "I felt like there was a cloud over my head like all the time... I didn't really feel like myself, like nothing that I liked to do really made me happy. I didn't really want to do anything." The student athlete explained that this experience/feeling was driven by the athlete being 
restricted from participation of her sport as well as the stress and fear of getting out of shape. Tracey (2003) found similar results in her interviews with injured athletes, discovering that injured student athletes' comparison of their fitness levels with teammates resulted in feelings of anxiety, tension, and self-doubt.

The two female student athletes listed other signs and symptoms during the interview, such as feeling depressed, angry, afraid, worried, stressed out, sad, excluded, frustrated, upset, and feeling left out. All three student athletes expressed how not being able to compete with their teams created most of the emotions described due to feeling like they were letting their team down. These comments are supported by the results of Tracey (2003), who found that attending practice provided the participants constant reminders of their loss of fitness, the feeling of letting their teammates down, and worsening their feelings of anxiety, frustration, and depression.

The current study found that 28 percent of the study sample met the criteria for possible depressive symptom concern (scoring 16 or higher on their CESD-R responses). These data confirm those of Yang et al. (2007), who reported that 21 percent of their participants scored 16 or higher for depressive symptoms on a similar CESD scale. Overall, these findings are concerning because they indicate a need for increased mental health support in collegiate athletics. The current study found an interesting linear relationship between social support satisfaction and CESD-R depressive symptom categories. Several studies support the idea that the greater the social support values, the lower amount of depression symptomatology present (Armstrong \& Oomen-Early, 2009; Clement \& Shannon, 2011; Baumeister \& Leary, 1995). This also supports the cognitive 
appraisal model and the importance of social support during stressful situations, as previously described.

The current study revealed a negative correlation between social support satisfaction and depression symptomatology scores in student athletes reporting a chronic injury. This suggests that student athletes have a greater desire/need of social support during these long-term injuries because such injuries require more time than acute injuries. No current literature could be found that examined social support variables and depression symptomatology in student athletes in general, or in those with chronic injuries.

\section{$\underline{\text { Limitations }}$}

This study has several limitations that should be noted. First, it was based on a convenience sample from only one university. There were only 30 injured participants, which was partially due to the data collection being completed during the middle of the spring season. If the study had been conducted during the fall and/or winter months when the training and competition load is more rigorous, there may have been a greater number of injured athletes available to participate in the study. There was also no baseline testing performed prior to the season or time of injury. It would be interesting to see how a student athlete's social support and depression symptomatology values change throughout the season, with or without injury. An important limitation of the interview findings was that they were based on a small convenience sample of injured athletes. The study was only able to enroll three student athletes who reported experiencing chronic injuries for the interview. It would be beneficial to have interview data from a larger 
sample of student athletes as well as student athletes who experienced acute and chronic injuries.

\section{Conclusion}

In summary, the current study confirmed gender characteristics regarding helpseeking behavior, trends of depression symptomatology, and social support preferences. A relationship between satisfaction of social support and depression symptomatology in chronically injured student athletes revealed an unexpected need for social support in these student athletes. Future research should consider this relationship and investigate the unique characteristics and situational factors of chronic injuries. This study identified important findings about reported depression symptomatology in current Division 1 college student athletes. It is hopeful that these findings can be used as evidence to promote the need for education and intervention support in athletic departments.

Overall, the findings from this study indicate a need for further research regarding social support and depression symptomatology, specifically examining injured and noninjured student athletes. Further, interventions should be considered, as this study suggests that depression symptomatology occurs in injured and non-injured student athletes. 


\section{References}

About CESD-R. (2013). Retrieved January 25, 2016, from http://cesd-r.com/about-cesdr/

Andersen, M. B., \& Williams, J. M. (1988). A model of stress and athletic injury:

Prediction and prevention. Journal of Sport and Exercise Psychology,10(3), 294306.

Armstrong, S., \& Oomen-Early, J. (2009). Social connectedness, self-esteem, and depression symptomatology among collegiate athletes versus nonathletes. Journal of American College Health, 57(5), 521-526.

Ballard, P. A. (1996). Athletic care and injury prevention services provided to high school student athletes in North Carolina: Opinions of athletic directors. NASSP Bulletin, 80(582), 106-112.

Baumeister, R. F., \& Leary, M. R. (1995). The need to belong: Desire for interpersonal attachments as a fundamental human motivation. Psychological Bulletin, 117(3), 497.CESD-R Explanation. (2008). Retrieved January 25, 2016, from http://cesdr.com/cesdr/

Brewer, B. W., Linder, D. E., \& Phelps, C. M. (1995). Situational correlates of emotional adjustment to athletic injury. Clinical Journal of Sport Medicine,5(4), 241-245.

Clement, D., \& Shannon, V. R. (2011). Injured athletes' perceptions about social support. Journal of Sport Rehabilitation, 20(4), 457.

Depression. (n.d.). Retrieved February 12, 2016, from https://www.nimh.nih.gov/health/topics/depression/index.shtml\#part_145396

Eaton, W. W., Muntaner, C., Smith C., Tien, A., Ybarra, M. (2004). Center for Epidemiologic Studies Depression Scale: Review and revision (CESD and CESD- 
R). In: Maruish ME, ed. The Use of Psychological Testing for Treatment Planning and Outcomes Assessment. 3rd ed. Mahwah, NJ: Lawrence Erlbaum; 2004:363-377.

Etzel, E. F. (2006). Understanding and promoting college student-athlete health: Essential issues for student affairs professionals. NASPA Journal,43(3), 518-546.

Giza, C. C., \& Hovda, D. A. (2001). The neurometabolic cascade of concussion. Journal of Athletic Training, 36(3), 228.

Gulliver, A., Griffiths, K. M., \& Christensen, H. (2012). Barriers and facilitators to mental health help-seeking for young elite athletes: a qualitative study. $B M C$ psychiatry, 12(1), 1.

Hootman, J. M., Dick, R., \& Agel, J. (2007). Epidemiology of collegiate injuries for 15 sports: Summary and recommendations for injury prevention initiatives. Journal of Athletic Training, 42(2), 311.

Lakey, B., \& Cohen, S. (2000). Social support theory and measurement. Social support measurement and intervention: A guide for health and social scientists, 29-52.

Mainwaring, L. M., Hutchison, M., Bisschop, S. M., Comper, P., \& Richards, D. W. (2010). Emotional response to sport concussion compared to ACL injury. Brain injury, 24(4), 589-597.

Messner, M. A. (1992). Power at play: Sports and the problem of masculinity. Boston, MA: Beacon.

National Institute of Mental Health. (2012). Depression and College Students [Brochure]. Retrieved February 12, 2016, from https://infocenter.nimh.nih.gov/pubstatic/NIH 12-4266/NIH 12-4266.pdf 
Sarason, I. G., Levine, H. M., Basham, R. B., \& Sarason, B. R. (1983). Assessing social support: The Social Support Questionnaire. J Pers Soc Psychol. 44(1)), 127-139.

Sarason, I. G., Sarason, B. R., Shearin, E. N., \& Pierce, G. R. (1987). A brief measure of social support: Practical and theoretical implications. J Soc Pers Relat. 4(4):497510.

Sarason, B. R., Sarason, I. G., \& Pierce, G. R. (1990). Social Supports: An Interactional View. New York, NY: Wiley;

Shumaker, S. A., \& Brownell, A. (1984). Toward a theory of social support: Closing conceptual gaps. Journal of Social Issues, 40(4), 11-36.

Smith, A. M., Stuart, M. J., Wiese-Bjornstal, D. M., Milliner, E. K., O'Fallon, W. M., \& Crowson, C. S. (1993, October). Competitive athletes: Preinjury and postinjury mood state and self-esteem. In Mayo Clinic Proceedings (Vol. 68, No. 10, pp. 939-947). Elsevier.

Tracey, J. (2003). The emotional response to the injury and rehabilitation process. Journal of Applied Sport Psychology, 15(4), 279-293.

Walker, N., Thatcher, J., \& Lavallee, D. (2007). Review: psychological responses to injury in competitive sport: a critical review. The Journal of the Royal Society for the Promotion of Health, 127(4), 174-180.

Wheeler, C. M. (2007). 10 Simple Solutions to Stress: How to Tame Tension \& Start Enjoying Your Life. New Harbinger Publications.

Wiese-Bjornstal, D. M., Smith, A. M., \& LaMott, E. E. (1995). A model of psychologic response to athletic injury and rehabilitation. Athletic training: sports health care perspectives, 1(1), 17-30. 
Wiese-Bjornstal, D. M., Smith, A. M., Shaffer, S. M., \& Morrey, M. A. (1998). An integrated model of response to sport injury: Psychological and sociological dynamics. Journal of Applied Sport Psychology, 10(1), 46-69.

Williams, K. L., \& Galliher, R. V. (2006). Predicting depression and self-esteem from social connectedness, support, and competence. Journal of Social and Clinical Psychology, 25(8), 855.

Yang, J., Peek-Asa, C., Corlette, J. D., Cheng, G., Foster, D. T., \& Albright, J. (2007). Prevalence of and risk factors associated with symptoms of depression in competitive collegiate student athletes. Clinical Journal of Sport Medicine, 17(6), 481-487.

Yang, J., Peek-Asa, C., Lowe, J. B., Heiden, E., \& Foster, D. T. (2010). Social support patterns of collegiate athletes before and after injury. Journal of Athletic Training, 45(4), 372-379. 
Appendix A

Demographic Survey

Subject \#:

\section{Demographic Information}

1. Age yrs

2. Gender (Circle one)

Male / Female

3. Academic Standing (Circle one) Freshman / Sophomore / Junior / Senior

Other

4. Sport (Circle one)

Basketball / Volleyball / Soccer / Softball /

Football / Track \& Field / Cross Country /

Golf / Tennis / Cheerleading

5. Experience in Competitive Sport (\# of Years) yrs

6. History of Injury- Include High School Participation to Current (Circle all that apply and specify injury details)

*An injury is defined as any physical damage to the body that restricts participation from sport for 1 or more days.

Head / Neck / Shoulder / Elbow / Wrist /

Hand / Back / Hip / Knee / Ankle / Foot

Other

Specify (1) type of injury, (2) Approximate date of injury, and (3) length of time injured/recovering from injury. For example: Ankle Sprain, March 2015, and 2 weeks 
7. Currently injured? (Circle one) Yes / No

Indicate injury:

*Restricted from participation of sport for 1 or more days

8. History of Anxiety or Depression? (Circle one)

Yes / No

If yes, indicate which condition and when it was diagnosed (Month and Year) 
Appendix B

Social Support Questionnaire 6

\section{Instructions:}

The following questions ask about people in your life who provide you with help or support. Each question has two parts. For the first part, list all the people you know, excluding yourself, whom you can count on for help or support in the manner described. Give the person's initials and their relationship to you (see example). Do not list more than one person next to each of the numbers beneath the question.

For the second part, circle how satisfied you are with the overall support you have.

If you have no support for a question, check the words "No one," but still rate your level of satisfaction. Do not list more than nine persons per question.

Please answer all questions as best you can. All your answers will be kept confidential.

\section{Example:}

Who do you know whom you can trust with information that could get you in trouble?

No one

1) T.N. (brother)

4) L.M. (friend)

2) T.N. (father)

5) L.M. (coach)

7) R.S. (friend)

3)

6)

8)

9)

How Satisfied?

$\begin{array}{llllll}6-\text { very } & 5-\text { fairly } & 4-\text { a little } & 3-\text { a little } & 2-\text { fairly } & 1-\text { very } \\ \text { satisfied } & \text { satisfied } & \text { satisfied } & \text { dissatisfied } & \text { dissatisfied } & \text { dissatisfied }\end{array}$


1. Whom can you really count on to be dependable when you need help?

No one

1)

2)

3)
4)

5)

6)
7)

8)

9)

How Satisfied?

$\begin{array}{llllll}6-\text { very } & 5-\text { fairly } & 4-\text { a little } & 3-\text { a little } & 2-\text { fairly } & 1-\text { very } \\ \text { satisfied } & \text { satisfied } & \text { satisfied } & \text { dissatisfied } & \text { dissatisfied } & \text { dissatisfied }\end{array}$

2. Whom can you really count on to help you feel more relaxed when you are under pressure or tense?

No one

1)

2)

3)
4)

5)

6)
7)

8)

9)

How Satisfied?

$\begin{array}{llllll}6-\text { very } & 5-\text { fairly } & 4-\text { a little } & 3-\text { a little } & 2-\text { fairly } & 1-\text { very } \\ \text { satisfied } & \text { satisfied } & \text { satisfied } & \text { dissatisfied } & \text { dissatisfied } & \text { dissatisfied }\end{array}$

3. Who accepts you totally, including both your worst and your best points?

No one

1)

2)

3)
4)

5)

6)
7)

8)

9)

How Satisfied?

$\begin{array}{llllll}6-\text { very } & 5-\text { fairly } & 4-\text { a little } & 3-\text { a little } & 2-\text { fairly } & 1-\text { very } \\ \text { satisfied } & \text { satisfied } & \text { satisfied } & \text { dissatisfied } & \text { dissatisfied } & \text { dissatisfied }\end{array}$


4. Whom can you really count on to care about you, regardless of what is happening to you?

No one

1)

2)

3)
4)

5)

6)
7)

8)

9)

How Satisfied?

6 - very $\quad 5$ - fairly $\quad 4$-a little $\quad 3$-a little $\quad 2$ - fairly $\quad 1$ - very satisfied satisfied satisfied dissatisfied dissatisfied dissatisfied

5. Whom can you really count on to help you feel better when you are feeling generally down-in-the dumps?

No one

How Satisfied?

$\begin{array}{llllll}6-\text { very } & 5-\text { fairly } & 4-\text { a little } & 3-\text { a little } & 2 \text {-fairly } & 1 \text {-very } \\ \text { satisfied } & \text { satisfied } & \text { satisfied } & \text { dissatisfied } & \text { dissatisfied } & \text { dissatisfied ied }\end{array}$

6. Whom can you count on to console you when you are very upset?

No one

1)

2)

3)
4)

5)

6)
7)

8)

9)

How Satisfied?

$\begin{array}{llllll}6-\text { very } & 5-\text { fairly } & 4-\text { a little } & 3-\text { a little } & 2-\text { fairly } & 1-\text { very } \\ \text { satisfied } & \text { satisfied } & \text { satisfied } & \text { dissatisfied } & \text { dissatisfied } & \text { dissatisfied }\end{array}$


To score SSQ6:

1. Add total number of people for all 6 items. (Max. is 54).

Divide by 6 for per item score. This gives you SSQ Number Score, or SSQN.

2. Total satisfaction scores for all 6 items. (Max is 36).

Divide by 6 for per item score. This gives you SSQ Satisfaction score or SSQS

3. You can also add up total number of people that are family members and that can give the SSQ family score. 


\section{Appendix C}

The Center for Epidemiological Studies Depression Scale Revised

For each statement, please indicate how often you have felt this way recently by selecting the option you most agree with.

\begin{tabular}{|c|c|c|c|c|c|}
\hline & $\begin{array}{l}\text { Not at } \\
\text { all } \\
\text { or less } \\
\text { than } 1 \\
\text { day } \\
\text { last } \\
\text { week. }\end{array}$ & $\begin{array}{l}\text { One or } \\
\text { two days } \\
\text { last } \\
\text { week. }\end{array}$ & $\begin{array}{l}\text { Three to } \\
\text { four } \\
\text { days } \\
\text { last } \\
\text { week. }\end{array}$ & $\begin{array}{l}\text { Five to } \\
\text { seven } \\
\text { days last } \\
\text { week. }\end{array}$ & $\begin{array}{l}\text { Nearly } \\
\text { every } \\
\text { day } \\
\text { for two } \\
\text { weeks. }\end{array}$ \\
\hline My appetite was poor. & & & & & \\
\hline I could not shake off the blues. & & & & & \\
\hline $\begin{array}{l}\text { I had trouble keeping my mind on what I } \\
\text { was doing. }\end{array}$ & & & & & \\
\hline I felt depressed. & & & & & \\
\hline My sleep was restless. & & & & & \\
\hline I felt sad. & & & & & \\
\hline I could not get going. & & & & & \\
\hline Nothing made me happy. & & & & & \\
\hline I felt like a bad person. & & & & & \\
\hline I lost interest in my usual activities. & & & & & \\
\hline I slept much more than usual. & & & & & \\
\hline I felt like I was moving too slowly. & & & & & \\
\hline I felt fidgety. & & & & & \\
\hline I wished I were dead. & & & & & \\
\hline I wanted to hurt myself. & & & & & \\
\hline I was tired all the time & & & & & \\
\hline I did not like myself. & & & & & \\
\hline I lost a lot of weight without trying to. & & & & & \\
\hline I had a lot of trouble getting to sleep. & & & & & \\
\hline I could not focus on the important things. & & & & & \\
\hline
\end{tabular}


Thank you for your participation in this study.

(1) If you would like the results of the surveys, please check the designated box below and contact the student investigator in person or by email at atiedens@pdx.edu There will be an opportunity for interested participants who are currently injured or recovering from an injury to participate in a 15-20 minute interview with the investigator. This interview will focus on your current injury, your social support networks, and how the injury/healing process has affected you emotionally. (2) If you are interested in participating in the interview please check the designated box below and provide an email for the investigator to contact you about further details.

Please send me survey results.

Please contact me with further details about the interview.

Email: 


\section{CESD-R Explanation}

1. Sadness (Dysphoria): Question numbers 2,4, 6

2. Loss of Interest (Anhedonia): Question numbers 8, 10

3. Appetite: Question numbers 1, 18

4. Sleep: Question numbers 5, 11, 19

5. Thinking / concentration: Question numbers 3, 20

6. Guilt (Worthlessness): Question numbers 9, 17

7. Tired (fatigue): Question numbers 7, 16

8. Movement (Agitation): Question numbers 12, 13

9. Suicidal ideation: Question numbers 14, 15

\section{Calculating the overall CESD-style symptom score}

The response values for each question are:

- Not at all or less than one day $=0$

- $1-2$ days $=1$

- 3-4 days $=2$

- 5-7 days $=3$

- Nearly every day for 2 weeks $=4$

The Total CESD-R Score is calculated as a sum of responses to all 20 questions.

\section{Determining categories}

The determination of possible depressive symptom category is based upon an algorithm with the following logic:

- Meets criteria for Major depressive episode: Anhedonia or dysphoria nearly every day for the past two weeks, plus symptoms in an additional 4 DSM symptom groups noted as occurring nearly every day for the past two weeks;

- Probable major depressive episode: Anhedonia or dysphoria nearly every day for the past two weeks, plus symptoms in an additional 3 DSM symptom groups reported as occurring either nearly every day for the past two weeks, or 5-7 days in the past week;

- Possible major depressive episode: Anhedonia or dysphoria nearly every day for the past two weeks, plus symptoms in an additional 2 other DSM symptom groups reported as occurring either nearly every day for the past two weeks, or 5-7 days in the past week;

- Subthreshhold depression symptoms: People who have a CESD-style score of at least 16 but do not meet above criteria;

- No clinical significance: People who have a total CESD-style score less than 16 across all 20 questions.

(CESD-R Explanation, 2008) 


\section{Appendix D \\ Interview Guide}

I am going to ask you some questions regarding your experience being injured and I want you to answer openly and honestly. Remember, everything that you say is confidential and if you are ever uncomfortable answering a question, please let me know and we can skip it.

1. Tell me about your injury...

-How long have you been injured? How long were/are you out?

-How did you feel when you first got injured? Compared to now?

-Have you ever been injured in the past?

-How have you been doing while being injured/hurt?

- Emotionally->Sad, mad, unmotivated, motivated to get back, frustrated, lonely, avoiding people/things

- What caused you to feel that way?

-How have you/do you cope with your injury/situation?

- Talking to someone, music, distractions, eating, alternative exercise, meditation, yoga, etc.

- Has that helped or made things worse?

2. Do you feel supported from friends/family/coaches/athletic trainers after being injured? How so?

-How has that affected you emotionally/mentally during this time of being injured?

-Who has been the most supportive during this time for you? (Can list a few resources)

-If you could change the ways you've been supported, how would you prefer to receive support from the resources previously listed?

-Can you think of a specific time where your support systems affected you emotionally after being injured (Positive or negative)?

3. If depression or anxiety is reported...

-Have you felt your depression or anxiety symptoms worsen after becoming injured? How so?

- What do you think has caused that?

-Do you currently seek out treatment for your depression or anxiety (before and after the injury)?

- What treatment? Has the treatment changed at all since you were injured?

Is there anything else you would like to add? Thank you for taking the time to discuss these questions with me and for answering openly and honestly. I will be analyzing all of the data for my thesis, which is due at the end of the term. If you would like information about my findings, please contact me directly and I will be happy to provide you the results after my thesis defense is completed. 


\section{Appendix E \\ Informed Consent}

You are invited to participate in a research study conducted by Alyssa Tiedens from Portland State University, School of Community Health. The researcher hopes to learn about Division 1 college athletes and how their mood is affected after experiencing an injury. This study is being conducted in partial fulfillment of the requirements for a master's degree and is under the supervision of Gary Brodowicz. You were selected as a possible participant in this study because you are a Division 1 Portland State University athlete.

If you decide to participate, you will be asked to answer questions about your history of injury, your current feelings/mood/behaviors, and your social support networks. The survey will be provided to you via email or in person in the Peter W. Stott Center and should take about 10 minutes to complete. While participating in this study, it is possible that you will be asked about topics that could create some discomfort. If you do not feel comfortable answering a question, please skip it and move on to the next question. If you are experiencing any emotional concerns after participating in the study, free counseling services are available on campus at the Center for Student Health and Counseling. You may not receive any direct benefit from taking part in this study, but the study may help to increase knowledge, which may help future college athletes in the future.

Information that is obtained in connection with this study will be made public in the researcher's written thesis that could include survey scores and information regarding your history of injury. However, any survey information that is shared will not include your name or any information (e.g., name, i.d. \#, etc.) that would allow your survey to be linked to you. by excluding all names and obvious identifying information. This information will be kept confidential by excluding your name from the survey, as well as storing the completed survey in a locked file cabinet, which will be secured behind two locked doors.

Your participation is voluntary. You do not have to take part in this study, and it will not affect your status at Portland State University. You may also withdraw from this study at any time without penalty or consequence.

If you have questions or concerns about your participation in this study, contact Alyssa Tiedens at atiedens@pdx.edu or (763) 232-6394. If you have concerns about your rights as a research subject, please contact Research and Strategic Partnerships, Market Center Building $6{ }^{\text {th }}$ floor, Portland State University, (503) 725-4288.

Your signature indicates that you have read and understand the above information and agree to take part in this study. The researcher should provide you with a copy of this form for your own records.

Signature

Print name
Date 


\section{Appendix F \\ Interview Informed Consent}

You are invited to participate in a research study conducted by Alyssa Tiedens from Portland State University, School of Community Health. The researcher hopes to learn about Division 1 college athletes and how their mood is affected after experiencing an injury. This study is being conducted in partial fulfillment of the requirements for a master's degree and is under the supervision of Gary Brodowicz. You were selected as a possible participant in this study because you are an injured Division 1 Portland State athlete.

If you decide to participate, you will be asked to answer questions about your history of injury, your current feelings/mood/behaviors, and your social support networks. The interview will be completed in the PSU team physician's office in the Peter W. Stott Center, and should take about 15-20 minutes to complete. The interview will be audio recorded on a cell phone, but the recording will be imported to a secure computer immediately following the interview. While participating in this study, it is possible that you will be asked about topics that could create some discomfort. If you do not feel comfortable answering a question, please ask to skip it and we will move on to the next question. If you are experiencing any emotional concerns after completing the interview, free counseling services are available on campus at the Center for Student Health and Counseling. You may not receive any direct benefit from taking part in this study, but the study may help to increase knowledge, which may help future college athletes in the future.

Information that is obtained in connection with this study will be made public in the researcher's written thesis, which includes quotations from interview responses. Any information that is shared with the research will remain anonymous. All names and obvious identifying information will not be included in the thesis. This information will be kept confidential by excluding your name from the interview transcript, as well as storing the interview recording on the researcher's personal computer, which is dual password protected.

Your participation is voluntary. You do not have to take part in this study, and it will not affect your status at Portland State University. You may also withdraw from this study at any time without penalty or consequence.

If you have questions or concerns about your participation in this study, contact Alyssa Tiedens at atiedens@pdx.edu or (763) 232-6394. If you have concerns about your rights as a research subject, please contact Research and Strategic Partnerships, Market Center Building $6^{\text {th }}$ floor, Portland State University, (503) 725-4288.

Your signature indicates that you have read and understand the above information and agree to take part in this study. The researcher should provide you with a copy of this form for your own records.

Signature

Date

Print name 


\section{Appendix G \\ Recruitment Email}

You are invited to participate in a study investigating Social Support and Depression Symptomatology Post Injury in Division 1 Athletes.

This is a research project being conducted by Alyssa Tiedens, a student at Portland State University, as part of her master's thesis. If you decide to participate, you will be asked to read and sign an informed consent form, complete a survey (both attached below) and return both to Alyssa Tiedens in the Athletic Treatment Center, located in the Peter W. Stott Center.

The inclusion criteria for the study includes being at least 18 years of age, a current Portland State University athlete, and currently not suffering/recovering from a concussion.

Any information that is obtained in association with this study will be kept strictly confidential. Your participation in this study is voluntary. You are not obligated to take part in this study, and it will not affect your status at Portland State University. You may withdraw from this study at any time without penalty or consequence.

You do not have to respond if you are not interested in this study. You may be contacted an additional time for your interest in the study, which you can simply disregard or decline.

Thank you for your time and consideration. I look forward to hearing from you.

Alyssa Tiedens 
Appendix $\mathrm{H}$

Human Subjects Approval

Post Office Box 751 503-725-2227 tel Portland, Oregon 97207-0751 503-725-8170

fax

\section{Human Subjects Research Review Committee hsrrc@pdx.edu}

Date: April 25, 2016

To: Gary Brodowicz and Alyssa Tiedens, School of Community Health

From: Karen Cellarius, HSRRC Chair

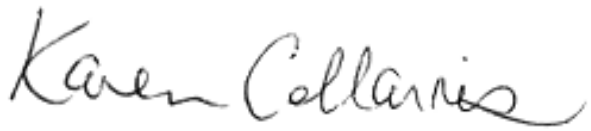

Re: HSRRC approval for your protocol, \#163757, entitled: "Social Support and Depressed Symptomology Post Injury in Division 1"

Approval-Expiration: April 25, 2016 - April 24, 2017 Review Type: Expedited, Categories 6 \& 7

In accordance with your request, the PSU Human Subjects Research Review Committee has reviewed your request for approval of the project referenced above for compliance with PSU and DHHS policies and regulations covering the protection of human subjects. The Committee is satisfied that your provisions for protecting the rights and welfare of all subjects participating in the research are adequate, and your project is approved. Please note the following requirements:

Approval: You are approved to conduct this research study only during the period of approval cited above; and the research must be conducted according to the plans and protocol submitted (approved copy enclosed).

Consent: Signed consent is required from all youth participants in this study

Changes to Protocol: Any changes in the proposed study, whether to procedures, survey instruments, consent forms or cover letters, must be outlined and submitted to the Committee immediately. The proposed changes cannot be implemented before they have been reviewed and approved by the Committee.

Continuing Review: This approval will expire on April 24, 2017. It is the investigator's responsibility to ensure that a Continuing Review Report on the status of the project is submitted to the HSRRC two months before the expiration date, and that approval of the study is kept current. The IRB offices does not send out notifications of expiration dates. The Continuing Review Report is available at www.rsp.pdx.edu/compliance_human.php and in the Office of Research and Strategic Partnerships (RSP).

Adverse Reactions and/or Unanticipated Problems: If any adverse reactions or unanticipated problems occur as a result of this study, you are required to notify the Committee immediately. If the issue is serious, approval may be withdrawn pending an investigation by the Committee.

Completion of Study: Please notify the Committee as soon as your research has been completed. Study records, including protocols and signed consent forms for each participant, must be kept by the investigator in a secure location for three years following completion of the study (or per any requirements specified by the project's funding agency).

If you have questions or concerns, please contact the Office of Research Integrity in the PSU RSP at 503725-2227. 